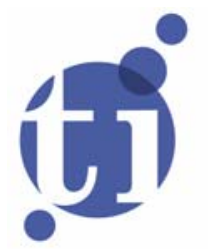

\title{
Score-Driven Systemic Risk Signaling for European Sovereign Bond Yields and CDS Spreads
}

Rutger-Jan Lange

Andre Lucas*

Arjen H. Siegmann

* Tinbergen Institute

Faculty of Economics and Business Administration, VU University Amsterdam, the Netherlands. 
Tinbergen Institute is the graduate school and research institute in economics of Erasmus University Rotterdam, the University of Amsterdam and VU University Amsterdam.

More TI discussion papers can be downloaded at http://www.tinbergen.nl

Tinbergen Institute has two locations:

Tinbergen Institute Amsterdam

Gustav Mahlerplein 117

1082 MS Amsterdam

The Netherlands

Tel.: +31(0)20525 1600

Tinbergen Institute Rotterdam

Burg. Oudlaan 50

3062 PA Rotterdam

The Netherlands

Tel.: +31(0)10 4088900

Fax: +31(0)10 4089031 


\title{
Score-Driven Systemic Risk Signaling for European Sovereign Bond Yields and CDS Spreads*
}

\author{
Rutger-Jan Lange $^{a} \quad$ André Lucas $^{b, c}$ Arjen Siegmann ${ }^{b}$ \\ (a) Erasmus Universiteit Rotterdam \\ (b) Vrije Universiteit Amsterdam \\ (c) Tinbergen Institute
}

\begin{abstract}
We compute joint sovereign default probabilities as coincident systemic risk indicators. Instead of commonly used CDS spreads, we use government bond yield data which provide a longer data history. We show that for the more recent sample period 2008-2015, joint default probabilities based on CDS and bond yield data yield similar results. For the period 1987-2008, only the bond yield data can be used to shed light on European sovereign systemic stress. We also show that simple averages of rolling pairwise correlations do not always yield intuitive systemic risk indicators.
\end{abstract}

Keywords: systemic risk, conditional default, credit default swaps, bond yields.

\section{Introduction}

In this chapter we investigate the robustness of systemic risk indicators based on alternative but related data sources. Our focus is on indicators based on the generalized autoregressive score methodology of Creal et al. (2013); see also Harvey (2013). In particular, we provide new empirical results for joint default probabilities based on score-driven models using historical government bond yield data versus CDS spread data. Whereas CDS data is the more common choice in the empirical literature for measuring sovereign systemic risk, the typical time span for obtaining reliable data is rather short. Bond yield data, by constrast, allow us to go further back in time and

*All authors thank the European Union Seventh Framework Programme (FP7-SSH/2007-2013, grant agreement 320270 - SYRTO) for financial support. Email addresses: r.j.lange@vu.nl, a.lucas@vu.nl, a.h.siegmann@vu.nl. 
therefore to test the adequacy of systemic risk measures over a much longer historical period.

The literature on systemic risk is large and expanding and relates to many different aspects of financial fragility as well as to the repercussions of financial stress on real economic activity. Rather than attempting to summarize this vast literature, we refer to some of the available surveys such as De Bandt and Hartmann (2000), Bisias et al. (2012), and Ang and Longstaff (2013). Here, we refer to systemic risk as either the simultaneous or conditional risk of financial stress for two or more sovereigns in the European context. Questions that are of particular interest relate to whether two countries are more likely to jointly default, rather than to whether one country defaults in isolation. Conversely, we are more interested in the probability of for example county $\mathrm{X}$ defaulting conditional on for example country $\mathrm{Y}$ already being in default, rather than the (marginal) probability of country X defaulting by itself. Such joint or conditional probability statements require a model for the dependence structure between different countries. It is precisely here that we use our time-varying parameter methodology to indicate which historical periods have experienced increased systemic vulnerability. We thus contribute to identifying systemic sovereign crises as in Laeven and Valencia (2013), but from a model-based perspective rather than an expert-based system.

Our focus in this paper is the comparison of systemic risk estimates based on CDS data versus bond yield data. CDS spreads are widely regarded as providing good estimates of credit risk, at least if the CDS is sufficiently liquid; see e.g. IMF (2013). For this reason, CDS data have been used in a variety of earlier studies, both for sovereigns, financial institutions, and corporates; see for example Rodríguez-Moreno and Peña (2013), Caporin et al. (2013), Lucas et al. (2014, 2016), Blasques et al. (2014), Creal et al. (2014), Oh and Patton (2016), Arakelian et al. (2016), and many more. Bond yields, on the other hand, may more easily suffer from confounding influences related to for example liquidity and flight-to-safety issues; see Pan and Singleton (2008). Still, bond yield data have the advantage that they are available over a much longer time span and a wider set of counterparties. For this reason, a number of authors have also used bond yield data to measure systemic sovereign debt risk; see for example Ang and Longstaff (2013) and Schwendner et al. (2015).

A key question that remains is whether systemic risk measures as computed on CDS versus bond yield data result in similar conclusions. Whereas most papers opt for one 
data source or the other, we explicitly focus on the comparison of the two before we interpret the more historical period that is covered by bond yield data, but not by CDS data. In this way, we are close to Caporin et al. (2013), who also explicitly use both sources of data. They find that for both types of data there is no evidence of sovereign contagion risk as a channel for increased system fragility. We, by contrast, focus on the dynamic relations of second moments as proposed in Lucas et al. $(2014,2016)$ to investigate the robustness of systemic risk measures.

Our findings are as follows. First, we find that the estimated probability of (at least) two sovereign defaults in the Eurozone in the period 2008-2015 is very similar for CDS and bond yield data. Important policy events lead to similar movements in both risk measures. Second, extending the sample over the period 1987-2008, we find increased systemic sovereign risk measures particularly during the early and mid 1990s. The Russian default, by contrast, only shows up as a very small and temporary increase in systemic risk measures. Third, when comparing our estimated joint default probabilities to direct market-observed measures of systemic risk, such as the pairwise correlations of crisis-countries, we find that these simple measures do not fully capture the joint default risk that we observe in the proposed risk-based measure. Our modelbased measures using bond yield data thus provide useful additional information to identify and monitor sovereign systemic risk events in the Eurozone over longer periods. By contrast, simple measures based on marginal risk indicators, such as the average of the highest three CDS spreads in the Eurozone, can already capture a substantial part of the dynamics multivariate systemic risk indicators.

The remainder of this paper is organized as follows. Section 2 introduces the model. Section 3 discusses the data. Section 4 presents the empirical results, and Section 5 concludes.

\section{Score-driven systemic risk models}

We now present the details of our score driven model for systemic risk surveillance. The model follows the set-up of Lucas et al. (2014). Let $\tilde{y}_{i, t}$ be the CDS spread or bond spread (vis-à-vis Germany, see section 3)

for country $i=1, \ldots, n$ and day $t=1, \ldots, T$. As in Alter and Beyer (2014), let $y_{i, t}$ 
denote the corresponding (log) differences,

$$
y_{i, t}= \begin{cases}\log \left(\tilde{y}_{i, t}\right)-\log \left(\tilde{y}_{i, t-1}\right) & \text { if } \tilde{y}_{i, t} \text { is a CDS spread, and } \\ \tilde{y}_{i, t}-\tilde{y}_{i, t-1} & \text { if } \tilde{y}_{i, t} \text { is a bond spread }\end{cases}
$$

We stack $y_{i, t}$ into the vector $y_{t}=\left(y_{1, t}, \ldots, y_{n, t}\right)^{\prime}$ and assume that

$$
y_{i, t} \mid \mathcal{F}_{t-1} \sim p\left(y_{i, t} \mid \Sigma_{t}, \nu\right), \quad \Sigma_{t+1}=\Omega+\beta \Sigma_{t}+\alpha\left(w_{t} y_{t} y_{t}^{\prime}-\Sigma_{t}\right)
$$

where $\mathcal{F}_{t}=\left\{y_{t}, r_{t-1}, \ldots\right\}$ is the information set spanned by all past observations; $p\left(\cdot \mid \Sigma_{t}, \nu\right)$ is a multivariate Student's $t$ distribution with zero mean, covariance matrix $\Sigma_{t}$, and degrees of freedom parameter $\nu ; w_{t}$ is a scalar weight matrix to be discussed further below; and $\Omega, \beta, \alpha$, and $\nu$ are static parameters or parameter matrices that need to be fixed or estimated. For the Student's $t$ distribution, Creal et al. (2011) prove that $w_{t} y_{t} y_{t}^{\prime}-\Sigma_{t}$ is proportional to the scaled derivative of the log predictive density $p\left(y_{t} \mid \Sigma_{t}, \nu\right)$ with respect to $\Sigma_{t}$, where we set

$$
w_{t}=\frac{1+(n+2) /(\nu-2)}{1+y_{t}^{\prime} \Sigma_{t}^{-1} y_{t} /(\nu-2)}
$$

such that $\Sigma_{t}$ follows the score-driven dynamics introduced by Creal et al. $(2011,2013)$ and Harvey (2013). As shown in Blasques et al. (2015), using the derivative of the log predictive density in (2) to update $\Sigma_{t}$ has information theoretic optimality properties. It provides a steepest ascent type improvement to the local likelihood function by updating $\Sigma_{t}$ to $\Sigma_{t+1}$ using the information in both the realization $y_{t}$ and the probabilistic model $p\left(y_{t} \mid \Sigma_{t}, \nu\right)$.

The above modeling approach was introduced for the computation of systemic risk indicators in Lucas et al. $(2014,2016)$. As our focus here is on the robustness of these indicators when using bond yield data rather than sovereign CDS data, we simplify the estimation problem of the model by setting $\Omega=0$ and $\beta=1$ to obtain integrated score dynamics as in Lucas and Zhang (2016). We can then write the recursion for $\Sigma_{t}$ as an exponentially weighted moving average recursion (EWMA) of the form

$$
\Sigma_{t+1}=(1-\alpha) \Sigma_{t}+\alpha w_{t} y_{t} y_{t}^{\prime}
$$

Furthermore, we set $\alpha=0.01$ and $\nu=4$. As Lucas et al. (2014) show, the main ad- 
vantage of using the degrees of freedom parameter $\nu<\infty$ is to capture the conditional fat-tailedness of the marginal distributions, and the robust volatility and covariance dynamics in (2). For the dependence structure in the current specific setting, the value of $\nu$ appears to be less of a concern. The robustness of the propagation system for the volatilities and covariances in (2) is obtained by the weight factor $w_{t}$, which follows directly from the expression of the score of the Student's $t$ distribution. Using $w_{t}$, aberrant values of $y_{t}$ are automatically downweighted by the expression $y_{t} \Sigma_{t}^{-1} y_{t}$ in the denominator of (3). The chosen value of $\nu=4$ lies in the empirically relevant range to accommodate both the conditional fat-tailedness of the marginals and the robustness of the transition equation for $\Sigma_{t}$.

To initialize the recursion for $\Sigma_{t}$, we use the sample covariance matrix from the first $N=200$ trading days. In case of the CDS spreads, this is the only initialization needed. For the bond yield data, countries enter the database as time goes on. Once a country enters the sample, we reset the covariance matrix to the then prevailing historical average over the past 200 trading days. Alternatively, we could let the new series enter the covariance more gradually by altering the recursion in (4) into

$$
\Sigma_{t+1}=A \Sigma_{t} A+B_{t} y_{t} y_{t}^{\prime} B_{t}, \quad A=\left(\begin{array}{cc}
\sqrt{1-\alpha} \mathrm{I} & 0 \\
0 & \mathrm{I}
\end{array}\right), \quad B_{t}=\left(\begin{array}{cc}
\sqrt{\alpha w_{t}} \mathrm{I} & 0 \\
0 & \mathrm{I} / \sqrt{N}
\end{array}\right)
$$

where $N=200$ is the initialization window length, and the matrices are partitioned to contain the old series in the top-left block, and the new series in the lower-right block. This approach ensures that $\Sigma_{t}$ always remains positive definite, while at the same time retaining the information built up on the covariance matrix for the series that were already in the sample. After $N=200$ days, the old recursion (4) applies. ${ }^{2}$

The above dynamic multivariate volatility model can be used to obtain probability statements about joint or conditional sovereign default. Focussing on the joint default probability, assume that the default of sovereign $i$ at time $t$ is given by $p_{i, t}$. The joint

\footnotetext{
${ }^{2}$ Further minor modifications are needed if countries enter the sample in partially overlapping windows that are smaller than 200 days. In that case, the dimension of the lower-right submatrices decreases and that of the upper-left matrix increases every time a country crosses the boundary of 200 days in the sample.
} 
probability of a default of sovereigns $i$ and $j$ is then given by

$$
p_{i j, t}=\operatorname{Pr}\left[y_{i, t}>F_{i, t}^{-1}\left(p_{i, t}\right), y_{j, t}>F_{j, t}^{-1}\left(p_{j, t}\right)\right]
$$

where $F_{i, t}^{-1}(\cdot)$ denotes the inverse (one-dimensional) cumulative Student's $t$ distribution with volatility $\Sigma_{i i, t}$, the $i$ th diagonal element of $\Sigma_{t}$. Because of the non-zero correlation between any two countries $i$ and $j$, the probability $p_{i j, t}$ in (6) is not equal to the product of the marginal probabilities, i.e. $p_{i j, t} \neq p_{i, t} p_{j, t}$. We obtain the probabilities in (6) for each day $t$ by simulating from the multivariate Student's $t$ with covariance matrix $\Sigma_{t}$ and counting the fraction of draws in the appropriate corner regions for given marginal default probabilities $p_{i, t}$.

To obtain the marginal default probabilities, we follow a simplified version of the approach proposed by O'Kane (2011). The core of the method is that we can look at the CDS premium as a discounted value of the risk neutral expected loss. For our purposes, approaximate the term structure by a flat yield curve, which we use for discounting. We also use a fixed risk neutral loss-given-default assumption of $L^{\star}$ percent, and a fixed risk neutral default default hazard rate $\pi^{\star}$. With $c$ denoting the CDS premium and $r$ the discount rate, we have

$$
\begin{aligned}
& \frac{c}{(1+r)}+\frac{c}{(1+r)^{2}}+\ldots \frac{c}{(1+r)^{T}}= \\
& \frac{\pi^{\star} L^{\star}}{(1+r)}+\frac{\left(1-\pi^{\star}\right) \pi^{\star} L^{\star}}{(1+r)^{2}}+\ldots \frac{\left(1-\pi^{\star}\right)^{T-1} \pi^{\star} L^{\star}}{(1+r)^{T}} \Longleftrightarrow \\
& c \cdot \frac{1-(1+r)^{-T}}{r}=L^{\star} \pi^{\star} \cdot \frac{1-\left(1-\pi^{\star}\right)^{T}(1+r)^{-T}}{r+\pi^{\star}},
\end{aligned}
$$

where default is assumed to strike at the end of each subperiod. The CDS premium is thus approximately a multiple of the risk neutral per period expected loss $L^{\star} \pi^{\star}$, where the multiple depends on $r$ and $\pi^{\star}$. For small enough values of $r$ and $\pi^{\star}$ and maturity $T$, the multiplication factor can be approximated by 1 , such that $\pi^{\star} \approx c / L^{\star}$. Using a default rate of $L^{\star}=50 \%$, we can then multiply the CDS spread by a factor two to obtain an approximate default hazard rate. For larger losses given default, the estimated default probability reduces accordingly. Note that in line with earlier literature, our estimates of default risk are risk neutral, and therefore typically higher than the physical probabilities. Though this affects the level of our systemic risk 


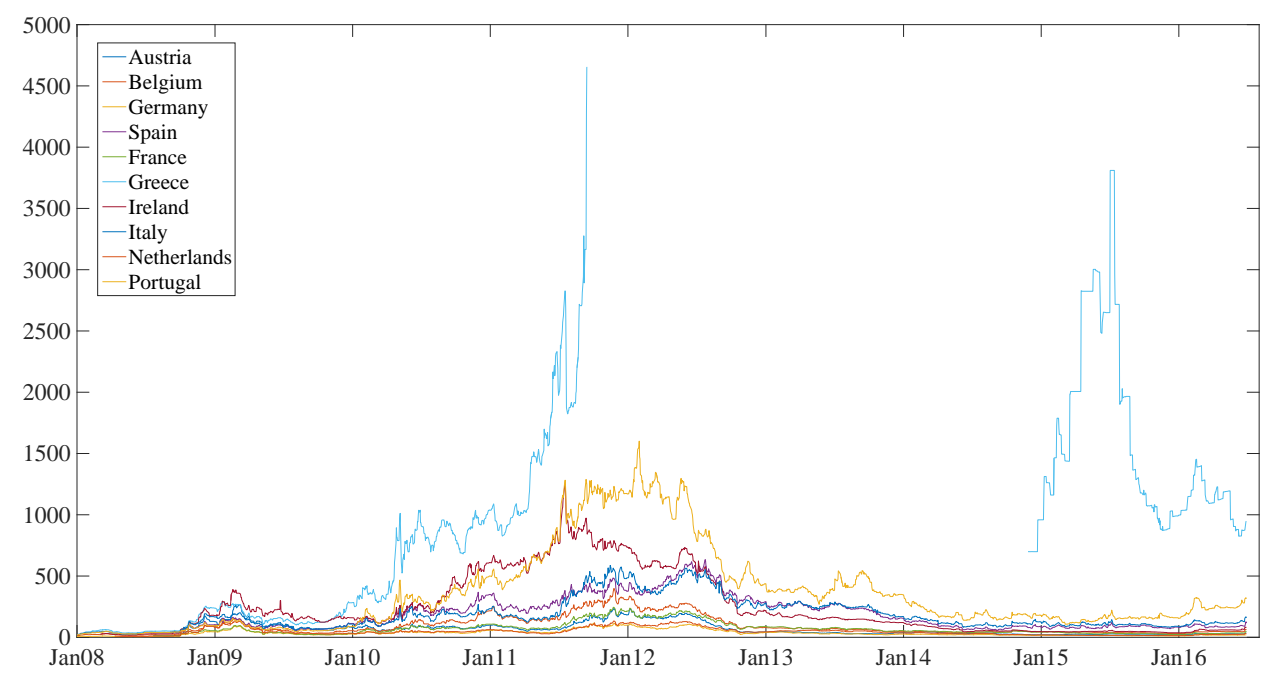

Figure 1: Sovereign CDS spreads 2008-2016

Daily sovereign CDS spreads from January 2008 until June 2016. Important events in the Euro zone crisis are listed in Table 2.

indicators, we do not expect it to affect the dynamics of the indicator too much, which is our main point of interest in this paper; compare the discussion in Lucas et al. (2014). The same argument applies to the risk neutral loss-given-default rate $L^{\star}$ used in the computations. In the case of bond yield data, we replace the CDS spread $c$ by the bond yield spread vis-à-vis Germany and follow the same approach as for CDS spreads. We are now ready to operationalize our systemic risk measures for European sovereign bond yield and CDS data.

\section{Data}

\subsection{CDS}

The CDS data are downloaded from Datastream and consist of daily CDS spreads on 5-year contracts for $n=10$ EU-zone sovereigns: Austria, Belgium, Germany, Spain, France, Greece, Ireland, Italy, the Netherlands and Portugal. The data sample period spans January 1, 2008 to June 28, 2016, giving 2216 observations (trading days) per country. As noted by IMF (2013), the market for sovereign CDS has been liquid since early 2008.

Figures 1 shows the evolution of CDS spreads for the 10 countries included in the 
sample. The CDS spreads for Greece exceed 5000 bps during some periods. While indicative of the extreme turmoil, we decide to exclude Greek CDS spreads from 16 September 2011, when they reached a level of 4652 basis points, until 27 November 2014, when they dropped back to around 700 basis points. At this point, Greece is treated as a new country in the sample. As a robustness check, we also run the model with Greece excluded entirely.

Table 1 Panel A provides summary statistics of our CDS returns as modeled by our score-driven volatility model from Section 2. We observe a large effect of Dutch CDS spreads jumping from 13 to 25 basis points on 2 October 2008 at the Dutch government participation in the rescue of Fortis Bank. The increase implies a log-return of $+65 \%$, causing a large kurtosis coefficient. If this observation is excluded, the standard deviation, skewness and kurtosis of Dutch CDS spreads are less extreme at 3.43, 0.65 and 17.53, respectively. However, because our dynamic model is robust with respect to such outliers, we keep this observation as is.

\subsection{Bonds}

Bond yield data are obtained from Datastream for the same group of 10 countries as the CDS spreads. We take daily yield-to-maturity quotes on 5-year sovereign bonds. The sample period differs per country, with starting dates varying between April 1977 (for Germany) and April 1999 (for Greece). The sample ends in June 2015, giving rise to between 4425 and 9953 observations per country.

Note that we do not model bond yields directly, but rather the spreads vis-à-vis Germany. Unlike the CDS spreads, our bond spreads are thus benchmarked against the creditworthiness of the German sovereign rather than against a risk-free asset.

Figure 2 shows the evolution of bond yields. The figure shows one line per country, and lines appear at the first date for which we have bond yield data. The first countries for which we have data are Germany (April 1977) and the Netherlands (1978). We have five countries from 1987 onwards. We choose to start our analysis of joint default probabilities in 1987 and extend it with new countries at the point that they enter the dataset.

The bond yield data show the familiar historical pattern. The yields converge until 1998, with the Greek bond yield entering the scene later and converging quickly there- 


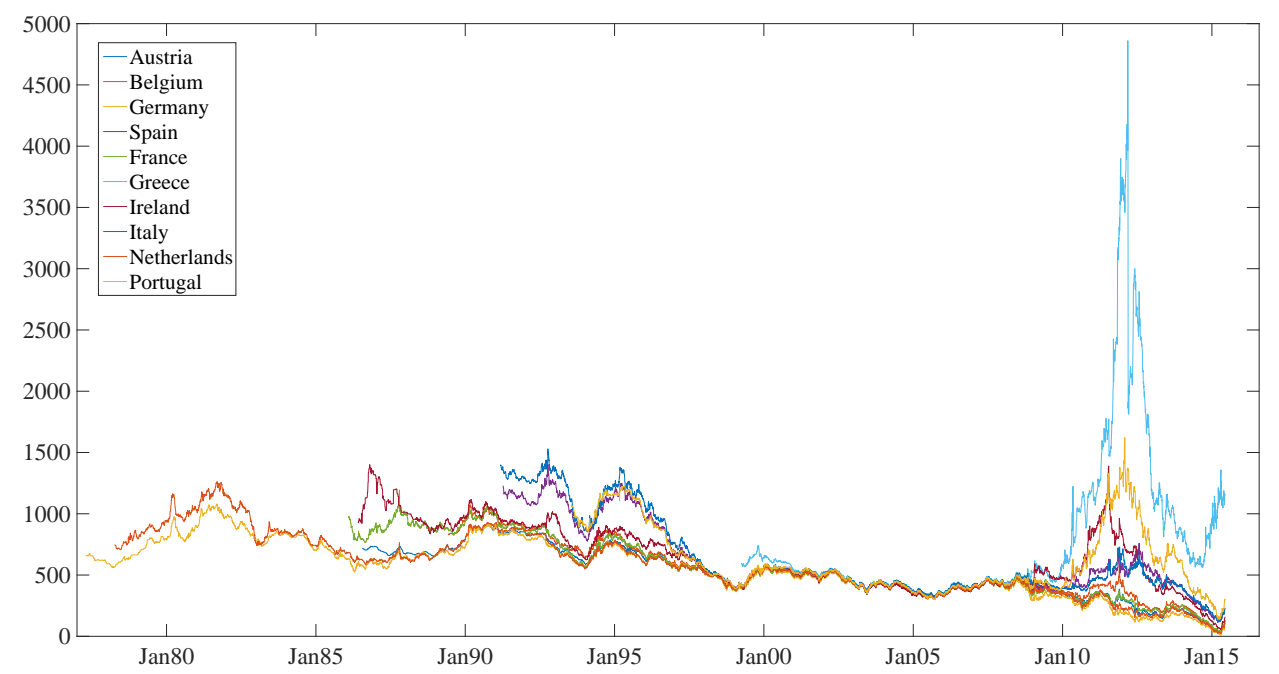

Figure 2: Bond yields historical 1977-2015

Historical bond yields for the sovereign debt of the European countries from April 1977 to June 2015. Our analysis starts in 1987, when the sample consists of 5 countries.

after. Yields remain in lock-step during the whole monetary integration process leading up to the Euro and thereafter, until the financial crisis and the subsequent sovereign debt crisis. Since then, the default risk of sovereign debt in a monetary union appears to be priced in by financial markets much more than before. We also see that towards the end of the sample, disparities between bond yields are again decreasing, Greece being the main exception due to the recurring sovereign debt and fiscal policy renegotiations with the EU and the IMF.

Table 1 panel B provides summary statistics of the bond yield changes. We note the 27.48 percentage point drop in Greek bond yields, which occurred on 12 March 2012, when the EU finalised the second bail-out package for Greece. When this extreme observation is excluded, the new minimum is -4.3 , which is somewhat more in line with the other minima. Similarly, the standard deviation, kurtosis and skewness figures are then less extreme at $0.25,5.08$, and 184.3, respectively. However, since the dynamic equation (4) is robust to outliers, we decide not to delete any bond observations.

Looking at the differences in skewness and leptokurtosis between CDS returns and bond yield changes in Table 1, we see that both the CDS and bond yield data are unconditionally fat tailed. There seems to be no clear pattern on whether the bond yield changes or the CDS returns are more non-normally distributed. We tackle this 


\section{Table 1: Summary Statistics}

Summary statistics bond yield changes and CDS log returns.Panel A contains summary statistics for CDS spread log returns for 10 Euro-area countries from the start of the series until 28 June 2016. Panel B contains summary statistics for bond yield changes for 10 Euro-area countries from the start of the series until June 2015.

\begin{tabular}{rrrrrrrrr} 
& \multicolumn{9}{c}{ Panel A: CDS (log) returns } \\
Country & Start date & Median & Mean & Stdev & Skew & Kurt & Min & Max \\
\hline Austria & $7 / 21 / 08$ & 0.00 & 0.05 & 3.76 & 1.59 & 17.9 & $-19 \%$ & $37 \%$ \\
Belgium & $1 / 1 / 08$ & 0.00 & 0.07 & 3.66 & 0.94 & 15.0 & $-24 \%$ & $39 \%$ \\
France & $7 / 2 / 08$ & 0.00 & 0.07 & 3.68 & 1.46 & 20.8 & $-23 \%$ & $41 \%$ \\
Germany & $1 / 1 / 08$ & 0.00 & 0.05 & 3.80 & 0.62 & 16.7 & $-28 \%$ & $39 \%$ \\
Greece & $1 / 1 / 08$ & 0.00 & 0.41 & 4.82 & 0.04 & 24.8 & $-50 \%$ & $36 \%$ \\
Ireland & $3 / 3 / 08$ & 0.00 & 0.05 & 3.64 & 0.15 & 25.9 & $-42 \%$ & $29 \%$ \\
Italy & $1 / 1 / 08$ & 0.00 & 0.09 & 4.37 & -0.23 & 15.9 & $-42 \%$ & $34 \%$ \\
Netherlands & $4 / 10 / 08$ & 0.00 & 0.06 & 3.71 & 3.01 & 57.0 & $-26 \%$ & $65 \%$ \\
Portugal & $1 / 1 / 08$ & 0.00 & 0.12 & 4.15 & -0.57 & 23.3 & $-56 \%$ & $30 \%$ \\
Spain & $7 / 21 / 08$ & 0.00 & 0.05 & 4.35 & 0.17 & 12.8 & $-37 \%$ & $35 \%$
\end{tabular}

\begin{tabular}{rrrrrrrrr} 
& \multicolumn{7}{c}{ Panel B: Bond yield changes } \\
Country & Start date & Median & Mean & Stdev & Skew & Kurt & Min & Max \\
\hline Austria & $7 / 22 / 86$ & 0.00 & 0.00 & 0.04 & 0.55 & 8.0 & -0.26 & 0.32 \\
Belgium & $6 / 6 / 89$ & 0.00 & 0.00 & 0.05 & 0.31 & 8.9 & -0.34 & 0.40 \\
France & $2 / 4 / 86$ & 0.00 & 0.00 & 0.05 & -0.61 & 17.7 & -0.87 & 0.46 \\
Germany & $4 / 19 / 77$ & 0.00 & 0.00 & 0.04 & 0.00 & 8.6 & -0.43 & 0.33 \\
Greece & $4 / 2 / 99$ & 0.00 & 0.00 & 0.49 & -40.12 & 2288.0 & -27.48 & 7.03 \\
Ireland & $5 / 28 / 86$ & 0.00 & 0.00 & 0.07 & 0.69 & 40.3 & -1.03 & 1.15 \\
Italy & $3 / 7 / 91$ & 0.00 & 0.00 & 0.07 & -0.03 & 16.8 & -0.78 & 0.67 \\
Netherlands & $4 / 4 / 78$ & 0.00 & 0.00 & 0.05 & -0.10 & 11.3 & -0.51 & 0.49 \\
Portugal & $7 / 19 / 93$ & 0.00 & 0.00 & 0.09 & 1.25 & 61.0 & -1.47 & 1.69 \\
Spain & $4 / 5 / 91$ & 0.00 & 0.00 & 0.06 & -0.61 & 16.1 & -0.88 & 0.43
\end{tabular}

via two channels. First, we allow for time varying volatilities, which reduces part of the unconditional fat-tailedness. Second, we introduce a conditional fat-tailed distribution, namely the Student's $t$ distribution.

\section{Empirical results}

\subsection{Systemic risk based on CDS vs bond spreads}

The main systemic risk measure in our analysis following Lucas et al. (2014) is the joint default probability which we define as the probability of two or more sovereign defaults, i.e.,

$$
p_{t}^{(2)}=\operatorname{Pr}\left[y_{i, t}>F_{i, t}^{-1}\left(p_{i, t}\right), y_{j, t}>F_{j, t}^{-1}\left(p_{j, t}\right) \text { for some } i \neq j\right] .
$$




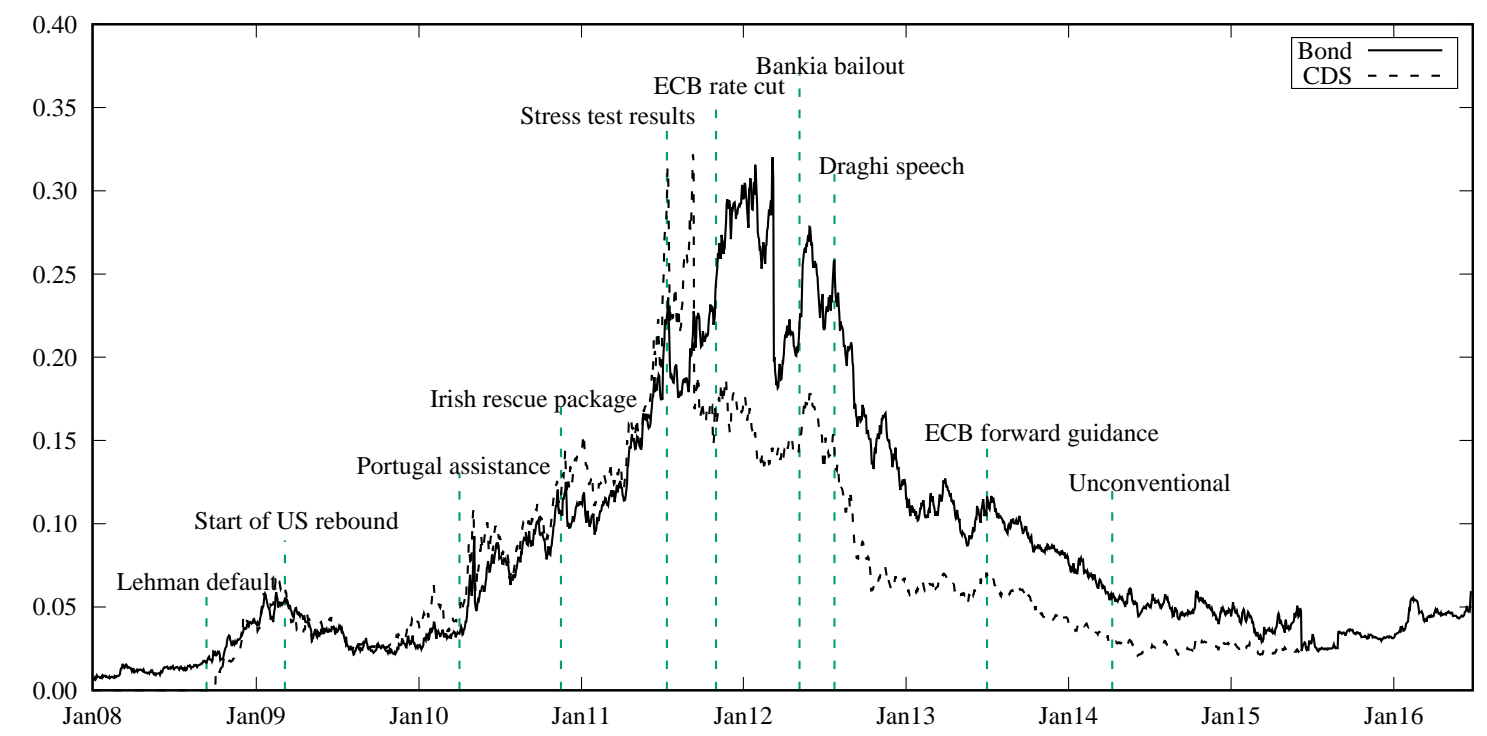

Panel A: Probability of $\geq 2$ defaults based on CDS and bond data (including Greece)

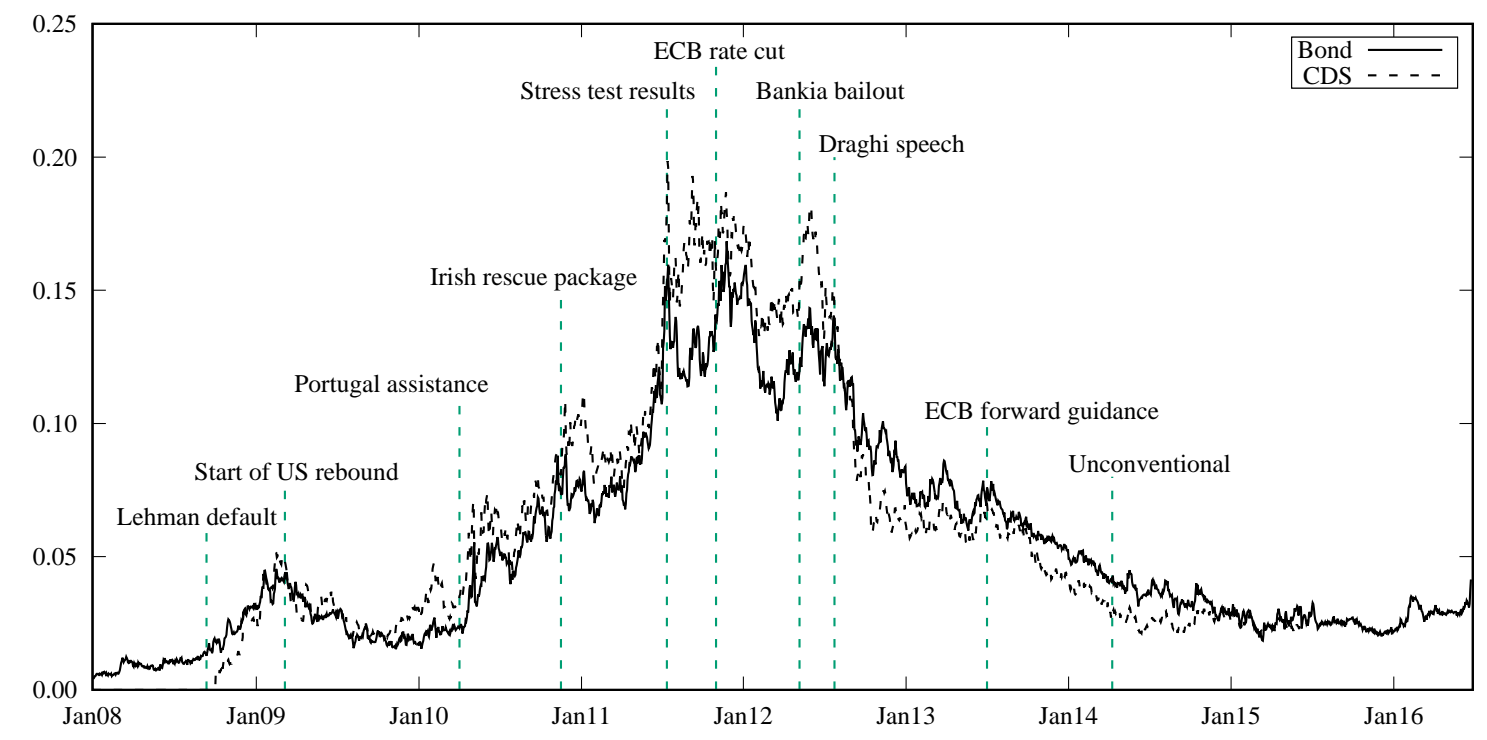

Panel B: Probability of $\geq 2$ defaults based on CDS and bond data (excluding Greece)

Figure 3: Probabilities of two or more defaults

The top panel includes all countries in the estimation. The bottom panel excludes Greece. The solid line is based on bond yields, while the dotted line is based on CDS spreads. The events are defined in Table 2.

A joint default probability for 3 or more defaults can be defined analogously. We compute $p_{t}^{(2)}$ separately for CDS and bond returns. The marginal default probabilities are estimated as described in Section 2. Our analysis on CDS spreads is hampered by the fact that CDS spreads for Greece are excluded from 16 September 2011 until 27 November 2014; see Section 3. However, the joint default measure is not necessarily affected: it measures the risk in the system and is not determined fully by any single 
Table 2: Important events for European sovereign default risk

\begin{tabular}{|c|c|c|}
\hline Event & Date & Description \\
\hline Lehman default & 15-Sep-08 & The US-bank Lehman brothers files for bankruptcy \\
\hline Start of US rebound & 10-Mar-09 & $\begin{array}{l}\text { US stocks begin a turnaround, with better than ex- } \\
\text { pected results for Citibank. }\end{array}$ \\
\hline Portugal assistance & 6-Apr-11 & $\begin{array}{l}\text { The resigning Prime Minister José Sócrates an- } \\
\text { nounces on television that the country, facing a sta- } \\
\text { tus of bankruptcy, would request financial assistance } \\
\text { to the IMF and the European Financial Stability Fa- } \\
\text { cility }\end{array}$ \\
\hline Irish rescue package & $21-$ Nov-10 & $\begin{array}{l}\text { Eurozone countries agree to a rescue package for Ire- } \\
\text { land from the European Financial Stability Facility } \\
\text { in response to the country's financial crisis. }\end{array}$ \\
\hline Stress test results & 15-Jul-11 & $\begin{array}{l}\text { The European Banking Authority (EBA) publishes } \\
\text { the results of its } 2011 \text { EU-wide stress test of } 90 \text { banks } \\
\text { in } 21 \text { countries. }\end{array}$ \\
\hline $\mathrm{ECB}$ rate cut & 3 -Nov-11 & $\begin{array}{l}\text { The ECB unexpectedly reduces the key interest rates } \\
\text { after fears of recession }\end{array}$ \\
\hline Bankia bailout & 25-May-12 & $\begin{array}{l}\text { Bankia SA negotiates a } 19 \text { billion euro bailout pack- } \\
\text { age from the Spanish government. Share trading is } \\
\text { suspended. }\end{array}$ \\
\hline Draghi speech & 26-Jul-12 & $\begin{array}{l}\text { Speech of ECB president Mario Draghi at the Global } \\
\text { Investment Conference in London: "Within our } \\
\text { mandate, the ECB is ready to do whatever it takes } \\
\text { to preserve the euro. And believe me, it will be } \\
\text { enough." }\end{array}$ \\
\hline ECB forward guidance & 4-Jul-13 & $\begin{array}{l}\text { The ECB reveals that key interest rates will remain } \\
\text { at present or lower levels for an extended period of } \\
\text { time. It is the first time that the ECB makes a com- } \\
\text { mitment regarding interest rates }\end{array}$ \\
\hline Unconventional & 12-Apr-14 & $\begin{array}{l}\text { The ECB president says that the ECB is ready to } \\
\text { use unconventional monetary policy instruments to } \\
\text { fight low inflation. }\end{array}$ \\
\hline
\end{tabular}

country. In principle, even though the level of systemic risk may appear lower when Greece is excluded from the analysis, the dynamics should remain similar. Furthermore, the Greek CDS spread still affects the creditworthiness of other countries and their CDS spreads, even if Greece itself is excluded from the sample. We therefore run our analysis with and without Greece to analyse whether the patterns of low and high systemic risk remain qualitatively similar. The results are shown in Figure 3.

Panel A of Figure 3 shows that the joint default probability dynamics are similar, regardless of whether they are based on CDS spreads or bond yields. Also when Greece leaves the CDS dataset, the joint default probabilities based on CDS and bond data diverge, but the relative movements over time remain highly similar.

Panel B shows the two joint default probabilities to be very similar over time when 
Greece is excluded. Moreover, the pattern of a rapid increase in systemic risk over the 2011-2014 period is retained. The analysis confirms our intuition on the similarity of both measures; i.e. those extracted from CDS changes and bond yield changes. It follows that bond yield changes are quite suitable for estimating the joint default probability. IMF (2013) suggests that the default risk of the strongest country in the union (Germany) could be good proxy for systemic risk. If systemic risk is priced as part of the bond yield of Germany itself, then it would be unwise to take bond spreads relative to Germany. Instead, it would be better to use outright bond yields. However, this approach would make the inputs of our model more sensitive to interestrate risk (which we factored out by subtracting German yields). Still, this might be an interesting avenue for further research.

\subsection{Joint default probability prior to 2008}

The analysis of the previous subsection can be extended to the pre-2008 period using only bond data. Figure 4 shows the joint default probability based on bond data for the entire sample. We observe an initial jump in the joint default probability when several countries enter the sample (early 1987). The peak in 1993 represents the ERM crisis following the exit of the British Pound on Black Wednesday, September 16, 1992. Interestingly, the 1995 peak represents the convergence of exchange rates and spreads of member countries. So, whereas the first peak (1992) represents market panic, the second peak (1995) reflects the settling down of markets. But peaks are classified as periods of increased systemic risk by our model, as the probability of a joint default is higher in both periods. After Greece joined the Euro in 2001, the joint default probability reaches its lowest point in history. The peak and decline of the 2008-2015 period are the same as in Figure 3.

\subsection{Conditional default probability}

To focus attention on the core of the Euro area and its connectedness, we exclude Greece from this analysis and focus on the probability of $\geq 2$ defaults conditional on $\geq 1$ default. The result is presented in Figure 5. It is clear that $P$ (\#defaults $\geq 2 \mid$ \#defaults $\geq 1$ ) increased substantially over the 1990s. Dusing the 2000s until the financial creasis, we notice a gradual decrease and some incidental temporary drops in the conditional default probability. Since the financial crisis, the conditional probability 


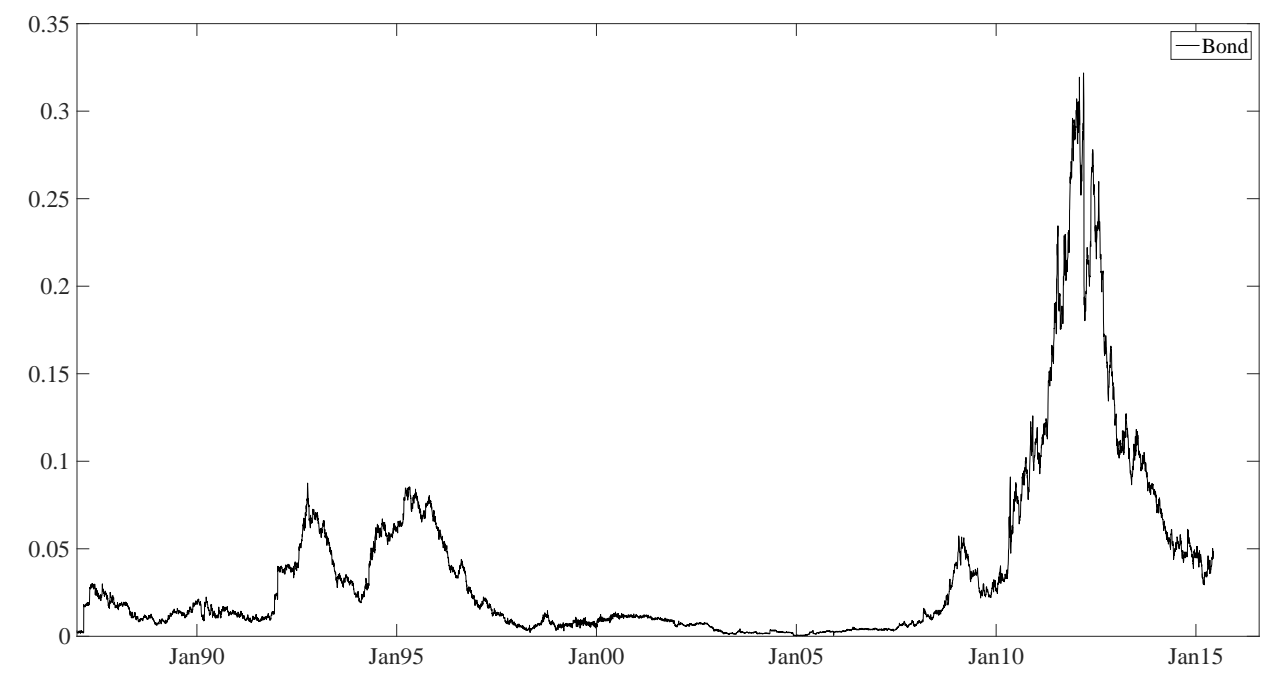

Figure 4: Bond-based joint default probability 1987-2015

Estimated probability of $\geq 2$ sovereign defaults using bond spread data, for the period 1987-2015.

has increased structurally to a higher level, where it remains until the very end of the sample. This suggest that the reduction in joint default risk since the crisis is caused mainly, and perhaps exclusively, by lower yields of stressed countries. At the same time, it appears the interdependence in the Euro area has actually increased. The yardstick of conditional default probability thus leads to the possibly worrying conclusion that systemic risk remains high even after the crisis.

\subsection{Decomposition of risk}

In order to decompose systemic risk by source, we note that the probability of two or more sovereigns going into default is affected by three factors: (i) the marginal probability of each country going into default; (ii) tail dependence, which describes the higher order dependence structure even if there are no correlations; (iii) the correlation structure, which describes the remaining (linear) dependence between countries. To capture component (i), we treat all default events as independent. Next, we capture component (ii) by adding our time varying multivariate Student's $t$ dependence structure, but with a unit correlation matrix. This introduces tail dependence, but no correlations. The increase in the joint default probability compared to setting (i) is attributed to the tail dependence. Finally, we also add the correlations component via the fully fledged model specification. The increase in the joint default probability 


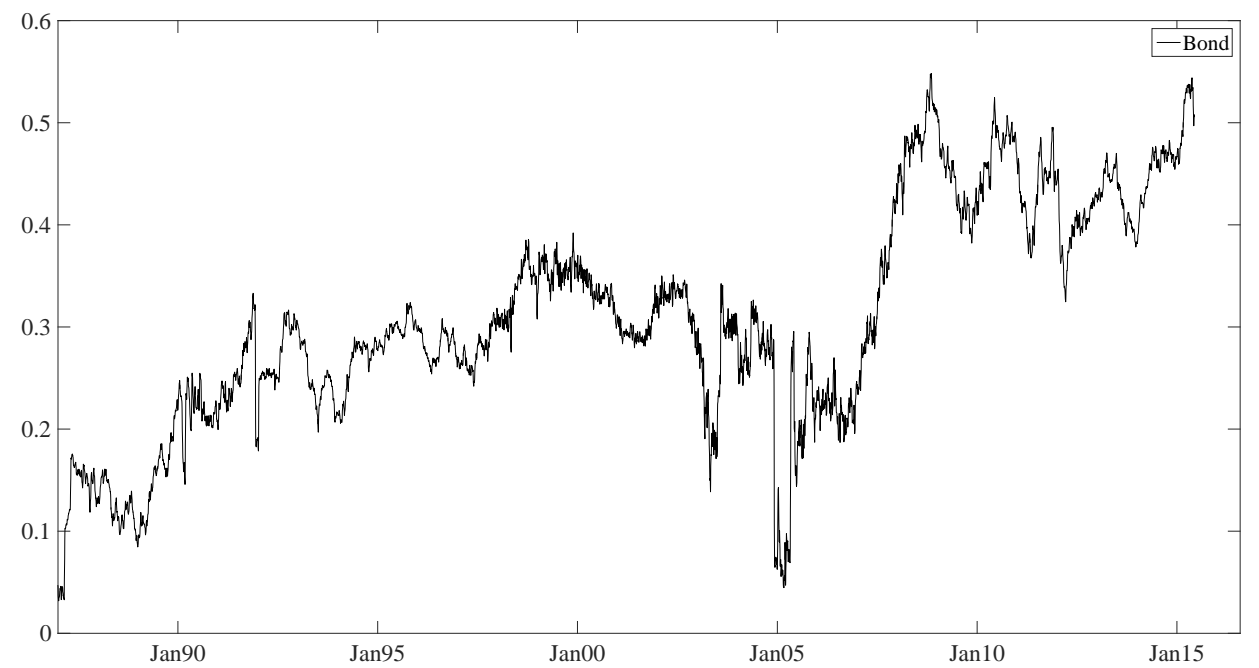

Figure 5: Conditional probability of two or more defaults

Conditional probability of two or more defaults calculated as $P$ (\#defaults $\geq 2 \mid \#$ defaults $\geq 1)=$ $P(\#$ defaults $\geq 2) / P(\#$ defaults $\geq 1)$.

compared to setting (ii) is attributed to the correlation component.

Figure 6 presents the decomposition results for the probability of two or more sovereigns defaults. Panel A displays the contribution of these effects, measured in percentage points, such that the sum the three contributions varies over time and is equal to the probability of a systemic event. Panel B, on the other hand, shows the relative contribution by source, measured as a percentage of a percentage, such that the sum of the three contributions is always equal to one hundred percent.

We observe that the dynamics of joint default risk are largely captured by the marginals. Particularly in times of crisis, the percentage of the systemic risk joint default probability captured by the marginals increases to around $50 \%$ in the 1990 s, $30 \%$ in the financial crisis, and $70 \%$ in the European sovereign debt crisis. Still, tail risk and correlation risk make up for a sizeable additional portion of systemic risk. Most interesting is the pattern towards the end of the sample. Clearly, the contribution of tail and correlation risk is largest during all periods where the perceived marginal risks are low (e.g., 1998-2007). At the end of the sample, however, the tail and correlation risks remain at peak levels compared to any other period in the sample where marginal risks are low. This suggests that markets perceive the European sovereign interconnectedness to remain high with all its possible implications for systemic fragility in Europe. 


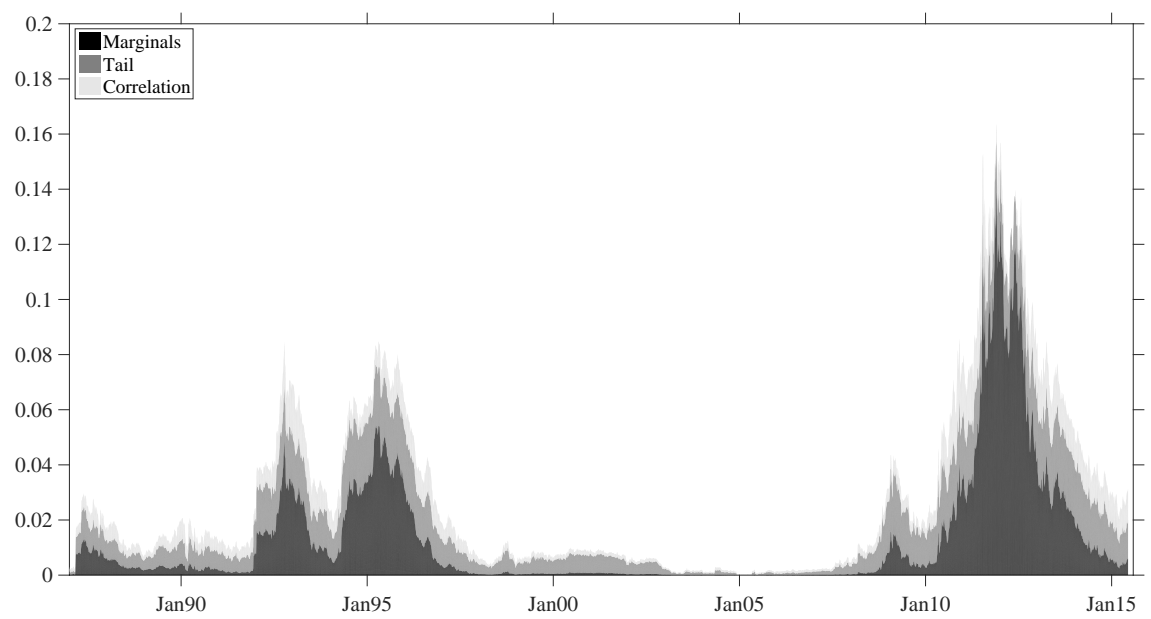

Panel A: Probability of \#defaults $\geq 2$ decomposed by source

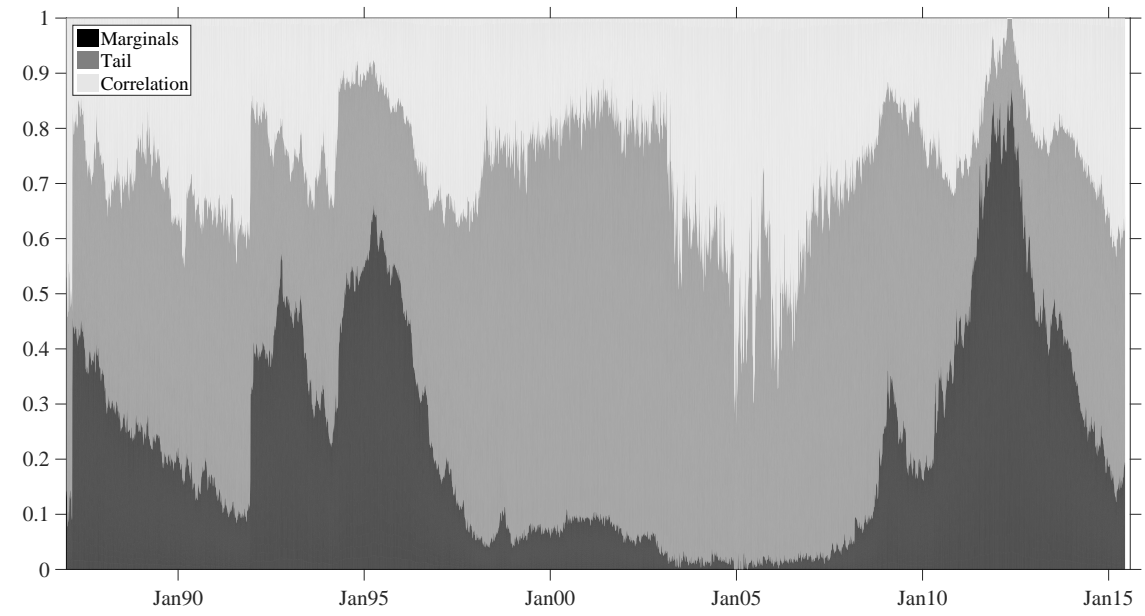

Panel B: Probability of \#defaults $\geq 2$ decomposed by source (percentage of percentage)

\section{Figure 6: Decomposition of the joint default probability}

Panel A and Panel B show a decomposition of the joint default probability, i.e. the probability of \#defaults $\geq 2$, decomposed by source: i.e. the part caused by the marginal probabilities, tail or correlation risk. Panel A (Panel B) shows the absolute (relative) contribution of these sources, such that their sum is equal to the probability of \#defaults $\geq 2$ (one hundred percent). As explained in the text, both panels exclude Greece. 
We note that Figure 6 excludes Greece. If Greece is included, the correlation between sovereigns sometimes lowers the probability of two or more defaults. It turns out that during the high peak of the crisis Greek bond returns were negatively correlated with those of other countries, possibly due to a flight-to-safety effect. By excluding Greece, we ensure that the correlation component almost always increases the joint default probability, as would be expected for a component of systemic risk. Still, even without Greece the flight-to-safety patterns in the market at the peak of the European sovereign debt crisis result in an almost negligible contribution of the correlation component to the systemic risk measure.

\subsection{Comparison with simple measures}

A practical and widespread approach for assessing sovereign stress consists of simply plotting bond yields and CDS spreads. For example, during the European sovereign crisis of 2010/2011, as well as during later Greek government announcements, the CDS spread of Greek sovereign bonds could be monitored on a daily basis - or even an intra-daily basis - in order to gauge market expectations of a Greek default. The decomposition results from the previous section are suggestive that a large part of the joint default dynamics may already be captured by such marginal default dynamics. In order to assess what can be learned from this direct approach, we construct simple variables that measure the dependence between countries.

For CDS data, we exclude Greece and take (i) the German spread and (ii) the average of the highest two CDS spreads. For bond data, we take (i) the average of the highest three spreads versus Germany and (ii) three rolling pairwise correlations between Italy, Spain and Portugal. Figure 7 compares the evolution of these simple measures against the joint or conditional probability measure of two or more sovereign defaults.

Panel A shows the CDS-based joint default probability $P$ (\#defaults $\geq 2$ ) against two simple measures. We see that the simple average of the two highest CDS spreads (excluding Greece) tracks $P$ (\#defaults $\geq 2)$ quite well. This is in line with the decomposition results in Figure 6, where we see that during the crisis the joint default probability is driven to a large extent by the marginal default probabilities. While the German CDS spread also peaks in the crisis, it appears that our joint default risk measure is driven more by stressed countries than by the benchmark.

Panel B shows that the relative movement of the bond-based probability $P$ (\#defaults $\geq$ 


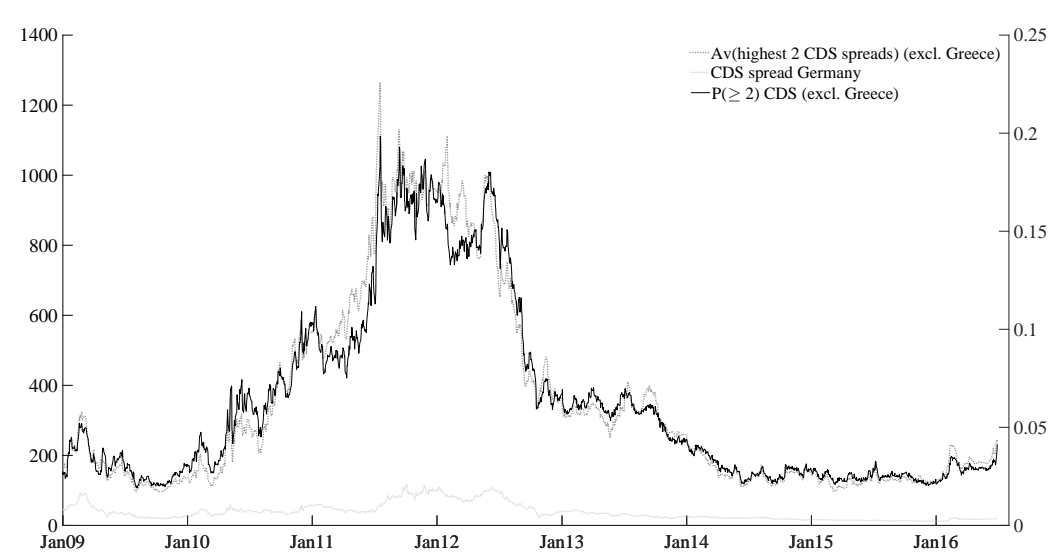

Panel A: CDS-based probability of \#defaults $\geq 2$ versus the average of the highest two CDS spreads (excluding Greece) and against the German CDS spread

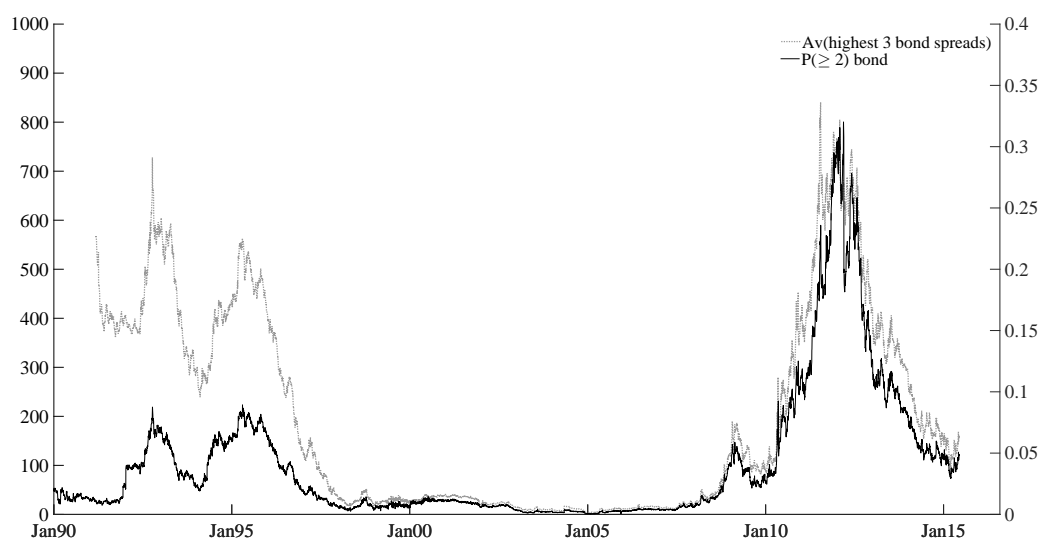

Panel B: Bond-based probability of \#defaults $\geq 2$ versus the average of the highest three bond spreads

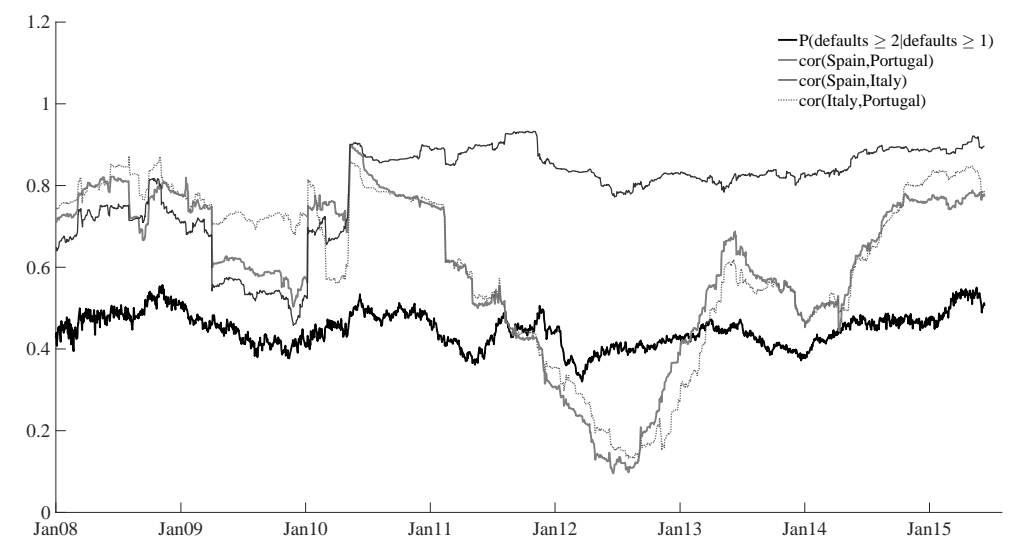

Panel C: Bond-based conditional probability $P$ (\#defaults $\geq 2 \mid$ \#defaults $\geq 1$ ) (excluding Greece) versus 200-day moving window correlation between Italy, Spain and Portugal

\section{Figure 7: Simple measures of systemic risk}

The joint default probability $P(\#$ defaults $\geq 2$ ) based on CDS and bond data is compared against simple measures based on those same data sets. Panel A shows the average CDS spread for the two highest spreads excluding Greece (dotted line) versus our estimated CDS-based joint default probability (solid line) and the German spread (grey line). Panel B shows the average bond spread for the three highest spreads (dotted line) versus our bond-based estimated joint default probability (solid line). Panel $\mathrm{C}$ shows the bond-based conditional default probability $P$ (\#defaults $\geq 2 \mid \#$ defaults $\geq 1$ ) against rolling correlations. 
2 ) is similar to the average of the three highest bond spreads. While there is still a substantial discrepancy during the earlier period, when the sample contains fewer countries, the similarity is particularly striking post-2000.

Panel C shows the bond-based conditional default probability $P$ (\#defaults $\geq 2 \mid \#$ defaults $\geq$ 1) over time (excluding Greece) together with three pairwise rolling-window correlations between countries that were vulnerable in the Euro crisis (Italy, Portugal and Spain). It can be seen that the rolling correlations go down during periods of systemic stress. This seems counter-intuitive, since lower correlations could be viewed as 'relieving' any risk of contagion. However, it turns out that this decreased correlation is often caused by a high spike in the bond yield of an individual country. While the correlation has gone down, both idiosyncratic and systemic risk may have increased: the spike in the bond yield of a single country off-sets the decrease in correlation such that systemic risk, i.e. the risk of two or more defaults, remains high, or even increases. We conclude that our probability measure of two or more defaults captures systemic risk in ways that are not easily observed from plotting pairwise correlations of bond yield changes in the market. In particular, the trend of $P$ (\#defaults $\geq 2 \mid \#$ defaults $\geq 1$ ) as discovered in Figure 5 cannot be captured using rolling-window correlation measures.

\section{Conclusion}

We computed the joint default probabilities for European sovereigns based on bond yields or CDS spreads. We found that both types of data yield similar results. This is comforting, as it allows for the use of bond yields to construct systemic risk measures that so far were predominantly developed for CDS spreads. Using this finding, we were able to infer joint probabilities of default in the Euro area for bond yields going back to 1987. The results are consistent with popular notions of when systemic risk was elevated, such as during the ERM crisis of 1992-1993. Moreover, the joint default probability in 2009 was only slightly lower than during the ERM crisis, suggesting that the measure is useful as an warning signal for sovereign systemic risk. Our decomposition further revealed that a large part of the joint default dynamics co-moves with the marginal default dynamics, such that also marginal measures can already convey useful information. The interconnectedness of the system, however, cannot easily be captured by simple measures such as rolling correlations, as these fail to capture the upward trend of conditional default risk as uncovered by our analysis. This paper 
therefore has shown that both simple and more sophisticated systemic risk measures have their merits, depending on the precise goal of the analysis.

\section{References}

Alter, A. and A. Beyer (2014). The dynamics of spillover effects during the european sovereign debt turmoil. Journal of Banking \& Finance 42, 134-153.

Ang, A. and F. A. Longstaff (2013). Systemic sovereign credit risk: Lessons from the us and europe. Journal of Monetary Economics 60(5), 493-510.

Arakelian, V., P. Dellaportas, R. Savona, and M. Vezzoli (2016). European sovereign systemic risk zones. Available at SSRN 2748481.

Bisias, D., M. D. Flood, A. W. Lo, and S. Valavanis (2012). A survey of systemic risk analytics. US Department of Treasury, Office of Financial Research (0001).

Blasques, F., S. J. Koopman, and A. Lucas (2015). Information-theoretic optimality of observation-driven time series models for continuous responses. Biometrika 102(2), 325-343.

Blasques, F., S. J. Koopman, A. Lucas, and J. Schaumburg (2014). Spillover dynamics for systemic risk measurement using spatial financial time series models.

Caporin, M., L. Pelizzon, F. Ravazzolo, and R. Rigobon (2013). Measuring sovereign contagion in europe. Technical report, National Bureau of Economic Research.

Creal, D., S. J. Koopman, and A. Lucas (2011). A dynamic multivariate heavytailed model for time-varying volatilities and correlations. Journal of Business and Economic Statistics 29(4), 552-563.

Creal, D., S. J. Koopman, and A. Lucas (2013). Generalized autoregressive score models with applications. Journal of Applied Econometrics 28(5), 777-795.

Creal, D. D., R. B. Gramacy, and R. S. Tsay (2014). Market-based credit ratings. Journal of Business \&5 Economic Statistics 32(3), 430-444.

De Bandt, O. and P. Hartmann (2000). Systemic risk: a survey.

Harvey, A. C. (2013). Dynamic models for volatility and heavy tails: with applications to financial and economic time series, Volume 52. Cambridge University Press.

IMF (2013). Global financial stability report, april 2013. 
Laeven, L. and F. Valencia (2013). Systemic banking crises database. IMF Economic Review 61(2), 225-270.

Lucas, A., B. Schwaab, and X. Zhang (2014). Conditional euro area sovereign default risk. Journal of Business Ef Economic Statistics 32(2), 271-284.

Lucas, A., B. Schwaab, and X. Zhang (2016). Measuring credit risk in a large banking system: econometric modeling and empirics. Journal of Applied Econometrics, forthcoming.

Lucas, A. and X. Zhang (2016). Score-driven exponentially weighted moving averages and value-at-risk forecasting. International Journal of Forecasting 32(2), 293302.

Oh, D. H. and A. J. Patton (2016). Time-varying systemic risk: Evidence from a dynamic copula model of cds spreads. Journal of Business $\&$ Economic Statistics, forthcoming.

O'Kane, D. (2011). Modelling single-name and multi-name credit derivatives, Volume 573. John Wiley \& Sons.

Pan, J. and K. J. Singleton (2008). Default and recovery implicit in the term structure of sovereign cds spreads. The Journal of Finance 63(5), 2345-2384.

Rodríguez-Moreno, M. and J. I. Peña (2013). Systemic risk measures: The simpler the better? Journal of Banking \& Finance 37(6), 1817-1831.

Schwendner, P., M. Schuele, T. Ott, and M. Hillebrand (2015). European government bond dynamics and stability policies: taming contagion risks. Journal of Network Theory in Finance 1(4). 